\title{
Formalized assessment of the sensitivity of economic sectors to the use of blockchain technologies (on the example of the Russian Federation)
}

\author{
Marat Safiullin ${ }^{1,2,}$ Leonid Elshin ${ }^{1,2,3}$ and Alia Abdukaeva ${ }^{1,2,3}$ \\ ${ }^{1}$ Kazan Federal University, Kazan, Russia \\ ${ }^{2}$ Center of Advanced Economic Research in the Academy of Sciences of the Republic of \\ Tatarstan, Kazan, Russia \\ ${ }^{3}$ Kazan National University of Science and Technology, Kazan, Russia
}

\begin{abstract}
Distributed data storage technologies are becoming an integral part of the modern economy and are beginning to have an increasing impact on the prospects and competitiveness of its development. This, in turn, predetermines the high growth rates of the blockchain technology market in the world. These dynamics will form changes not only in the IT markets, but also in the entire financial and economic systems, penetrated with information, digital decisionmaking processes. In this regard, relying on the functional capabilities of distributed data storage technologies, as well as taking into account the high dynamics of the processes of their penetration into the economic environment, it seems to be a very important and urgent task to develop methodological approaches to assess the risks and opportunities for the national economic system in the context of future changes. It is important to note, that the solution of the problem should, in order to objectify the results, rely on the methods of formalized analysis using the tools of economic and mathematical modeling. Based on this approach to the study of the academic and research problem, the work proposes an algorithm for assessing the influence of blockchain technologies on the dynamics of transformation of key development parameters of separate sectors of the economy. Methodologically, the calculations are based mainly on the construction of a cointegration model, that allows to determine the main effects and potential impact of possible changes in certain areas of economic activity as part of the penetration of blockchain technologies into the economic environment.
\end{abstract}

\section{Introduction}

Assessing the role of blockchain technologies in the modern developing world, their possible influence on macroeconomic generation, it should be stated, that individual countries have been actively moving towards the development and integration of the technologies under consideration into the economic environment in recent years. As an 
illustration, it is possible to give an example of the People's Republic of China, where "since May 2020, the national cryptocurrency of the Central Bank of China (DCEP) has been put into turnover" [1]. A number of Chinese banks already in 2020 began to apply distributed data storage technologies in their operational activity in terms of making payments, accounting for digital accounts, keeping a big data register and other purposes.

No less actively and intensively, distributed data storage technologies are being integrated into the economic turnover of a number of developed and developing countries of the world, both in terms of promising projects, declared by financial organizations (including regulators), and in terms of current projects being implemented in this area [2.3].

Thus, it should be stated about the extremely high level of significance and relevance of the issue of studying the influence of blockchain technologies on the parameters of socio-economic development, including the development of methods for a formalized assessment of such consequences. Meanwhile, in should stated with regret, that, despite the progressive interest of the expert and scientific community in distributed data storage technologies, there is both a fragmentation of views on the solution of the issue raised and the absence of unified approaches to a formalized assessment of possible generated opportunities and risks. At the same time, in the vast majority of cases, the positions of the authors tend to believe, that studying this kind of issues is extremely relevant, significant from a practical and scientific point of view, and require the development of an appropriate methodological apparatus. For example, this position can be found in the works of E. A. Pekhtereva [4], R.K. Nurmukhametov, P.D. Stepanov, T.R. Novikova [5], Yu.A. Konopleva, V.N. Kiseleva, S.E. Cheremnykh [6] and others.

Foreign scientists also pay extremely close attention to the raised problems. Most of the works of foreign researchers note the need for the closest attention to the studying blockchain technologies, both from the standpoint of qualitative and quantitative analysis [7-11].

Relying on the stated relevance of the issue and the indicated methodological "gaps" in relation to the subject of the research, the purpose of this work is to build and test models of scenario forecasting of the development of separate sectors of the national economy within the framework of the diffusion of blockchain technologies.

\section{Research Methodology}

Abstracting from the risks and threats in this research, posed by the integration of blockchain technologies into the financial and real sectors of the economy, the authors attempt to build a model, that assess the influence of the technologies under study on the possible dynamics of certain types of economic activity (using the example of the Russian Federation).

It is important to emphasize, that the development of economic sectors is characterized by heterogeneity and differentiation, both in terms of dynamics and in terms of their sensitivity to transformations in the external and internal environment. The integration of blockchain technologies into the economic environment of the national economic system will undoubtedly reflect on the key parameters of the development of economic activity in the same uneven and disproportionate way. However, the question of how fair the hypothesis and assumption are, is it possible to more or less objectively solve it within the framework of the development and use of special approaches, based on the methods of empirical analysis, including the use of mechanisms and tools of economic and mathematical modeling. 
Developing this research paradigm, the authors make an attempt to develop an appropriate methodological toolkit, which will be tested on the example of certain types of economic activity corresponding to the OKVED codes (Russian National Classifier of Types of Economic Activity).

The work used quarterly data for the period from 2008 to 2019 from official sources [14]. The calculations were carried out using the Eviews statistical package. Table 1 shows the variables of the developed models for certain types of economic activity, their legend and data sources. The dimension of the sample allows for calculations, since it is greater, than the set critical values of the Dickey-Fuller statistics.

Table 1. Description of the variables of the developed model.

\begin{tabular}{|c|c|c|}
\hline Variable & Designation & Data source \\
\hline \multicolumn{3}{|l|}{ Dependent } \\
\hline $\begin{array}{l}\text { Gross value added (in the context of each analyzed } \\
\text { sector of the Russian economy), billion rubles }\end{array}$ & VDS & Rosstat \\
\hline \multicolumn{3}{|l|}{ Independent } \\
\hline Stock market trading volume, RUB billion & & Moscow Exchange \\
\hline $\begin{array}{c}\text { Money transfers through the payment system of the } \\
\text { Bank of Russia using translation services / settlement } \\
\text { systems, billion rubles }\end{array}$ & & $\begin{array}{l}\text { Central Bank of } \\
\text { Russia }\end{array}$ \\
\hline $\begin{array}{l}\text { Total profit / loss of operating credit institutions, RUB } \\
\mathrm{mln}\end{array}$ & & $\begin{array}{c}\text { Central Bank of } \\
\text { Russia }\end{array}$ \\
\hline
\end{tabular}

The research of the dependencies between financial (stochastic) time series can be carried out using the method of cointegration analysis, where the cointegration equation is of the form:

$$
\Delta \mathrm{Yt}=\rho \mathrm{Yt}-1+\mathrm{i}=1 \mathrm{~m}-1 \mathrm{Ti} \Delta \mathrm{Yt}-\mathrm{i} \varphi \mathrm{Xt}+\varepsilon \mathrm{t}
$$

and

In a accumulated form, Figure 1 shows a graphical interpretation of the algorithm for assessing the influence of diffusion of blockchain technologies on the development of sectors of the national economy. 


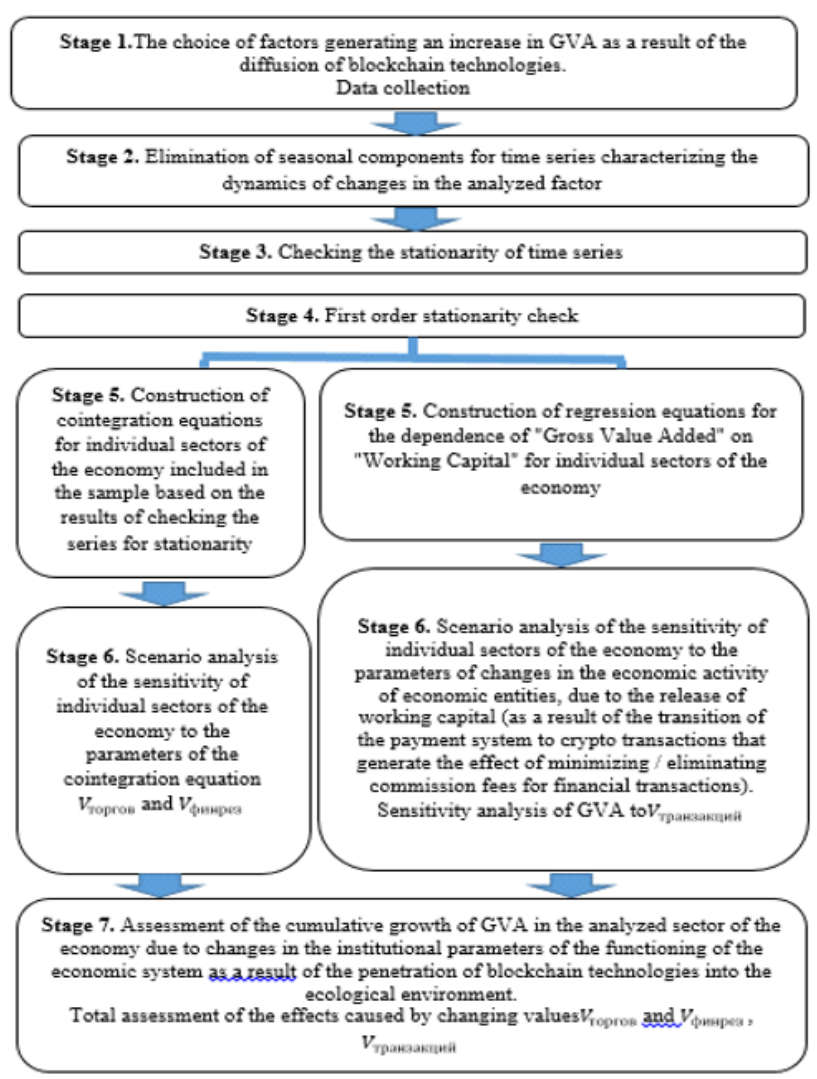

Fig. 1. Graphic interpretation of the algorithm for assessing the influence of diffusion of blockchain technologies on the development of sectors of the national economy.

\section{Findings}

According to the results of testing the analyzed time series for their stationarity, the integrated series of the first order are the series, characterizing the development parameters of the following sectors of the Russian economy:

- agriculture;

- mining;

- manufacturing industries;

- trade;

- financial and insurance activity;

- transportation and storage;

- public administration and military security; social security;

- activity in the field of health service and social services.

The identified sectors of the economy are suitable for applying the method of cointegration research and formed the basis for further iterations.

In accordance with the proposed research algorithm (Figure 1), for each type of economic activity, that fell into the one under study, according to the results of assessing the stationarity of the series, the sample, the corresponding cointegration equations are composed. The results are shown in Table 2. 
Table 2. Results and data of the statistical significance of the cointegration equations in the context of the analyzed types of economic activity, included in the studied sample.

\begin{tabular}{|c|c|c|c|c|}
\hline & \multicolumn{3}{|c|}{ Cointegration equation parameters } & \\
\hline & $\begin{array}{l}\text { Stock market } \\
\text { trading } \\
\text { volume }\end{array}$ & $\begin{array}{c}\text { The number of } \\
\text { money transfers } \\
\text { made through the } \\
\text { payment system of } \\
\text { the Bank of Russia, } \\
\text { mln. }\end{array}$ & $\begin{array}{c}\text { Balanced } \\
\text { financial result } \\
\text { of organizations' } \\
\text { activities, RUB } \\
\text { bln }\end{array}$ & \\
\hline agriculture & 0.000852 & 0.652552 & 0.04299 & 0.79 \\
\hline mining & 0.140868 & 1.844097 & 0.300956 & 0.7 \\
\hline $\begin{array}{c}\text { manufacturing } \\
\text { industries }\end{array}$ & 0.061163 & 7.250821 & 0.155 & 0.80 \\
\hline trade & -0.003355 & 5.800934 & 0.070829 & 0.87 \\
\hline $\begin{array}{c}\text { financial and } \\
\text { insurance activities }\end{array}$ & 0.034893 & 0.472347 & 0.047427 & 0.76 \\
\hline $\begin{array}{l}\text { transportation and } \\
\text { storage }\end{array}$ & 0.000803 & 0.635689 & 0.005392 & 0.62 \\
\hline $\begin{array}{l}\text { public administration } \\
\text { and military security; } \\
\text { social Security }\end{array}$ & 0.014 & 0.07 & 0.007 & 0.75 \\
\hline $\begin{array}{c}\text { activities in the field } \\
\text { of health and social } \\
\text { services }\end{array}$ & 0.004177 & 0.637559 & 0.009911 & 0.84 \\
\hline
\end{tabular}

All the composed equations, included in the sample, have a high coefficient of determination (R-squared), which indicates their statistical significance.

Possible effects, caused by the adjustment of the analyzed factors of the cointegration model (V_trades and V_(financial rez.), V_(transactions)) as a result of the penetration of blockchain technologies into the system of economic relations, are shown in Table 3.

The expected, in accordance with the scenario analysis, increase in the value of the factors is predetermined by the application of the basic scenario assumptions:

A) an increase in the efficiency of credit institutions.

- for operational risks, a reduction in the rate of reservation of operational risks by $20 \%$ from $12.5 \%$ to $10 \%$ of the average value of financial results over the past three years; - for credit risks, a scenario was selected, that provides for a $25 \%$ reduction in doubtful and problem loans. This scenario is attributed to the base one and provides for the minimum possible effects, thereby, practically ensuring the possible results, generated in the banking sector in the direction of "Lending" within the framework of the use of blockchain technologies.

The aggregate increase in financial results due to the implementation of these scenarios is estimated at 88.5 billion rubles per year.

B) The influence of blockchain technologies on the process of transformation of the payment system.

As a baseline scenario, within the framework of the analysis of the sensitivity of GDP to an increase in capital availability of economic units as a result of the transition of the payment system to crypto transactions, the most conservative of the considered scenarios was adopted, which provides, in accordance with the estimates, an increase in the liquidity of economic entities to 128 billion rubles, as the result of the transition of $10 \%$ of the current volume of the national payment system to the crypto environment.

C) Adjustments to the trade volume in the stock market as a result of the penetration of blockchain technologies (socialization of investment activity). 


\section{Discussion}

According to the MICEX, in 2019 the trade volume in the stock, money, foreign exchange and commodity markets of the Russian Federation amounted to 778,155 billion rubles. The average brokerage fee for leading brokers in 2019 corresponds to $0.3 \%$ of the sum of transaction. Thus, it can be concluded, that commission fees corresponded to the value of 2,334.465 billion rubles, which corresponds to about 1,325 rubles per 1 resident of the Russian Federation. Using the developed equation, that assesses the interrelation between the average per capita population income and the trade volume, it was found, that an increase in household income by 1,325 rubles contributes to a quarterly increase in trade volumes on the MICEX by 462.61 billion rubles.

Next, a sequence of calculations is presented, that assess the level of increase in gross value added as a result of the penetration of blockchain technologies into the national economy, in terms of a specific sector of the economy. The sequence of iterations is presented below using the example of the type of economic activity "Agriculture":

1. Relying on the data of the scenario analysis of the exogenous factors of the cointegration model V_(financial rez.) and V_trades in accordance with the previously calculated effects (Table 3 ), the sensitivity of the gross value added of the studied sector to changes in the analyzed parameters is determined.

2. To determine the parameter, assessing the influence of the transformation of the payment system as a result of its transition to crypto transactions, a separate regression equation is composed, where the GVA of the sector of the economy under study acts as an endogenous variable, and its working capital (in billion rubles) as an exogenous variable. This methodological approach is due to the fact, that in the resulting cointegration equation the explanatory factor V_(transactions) characterizes the overall change in the volume of funds transfer. Since the transition of the payment system to the crypto environment will not affect the volume of funds transfers, made through the Bank of Russia payment system, the effect of "communicating vessels" arises - the transition of payments from the fiat environment will lead to a proportional growth of the payment system, based on the use of digital money.

For example, for the type of economic activity "Agriculture", considered here as an example, the equation, characterizing the degree of influence of a change in the working capital of a given sector of the economy on a change in its gross value added, has the form:

$$
\mathrm{Y}=2,72 \mathrm{x}-1,009.86
$$

Substituting into this equation the expected increase in working capital for the sector under study (in proportion to the total increase in working capital in the economy as a whole $(+128$ billion rubles, Table 3$)$ due to the transition of $10 \%$ of transactions to the crypto environment (baseline scenario for analysis)), the effect of growth in gross value added (GVA) of this type of activity is determined within the framework of the penetration of blockchain technologies into the payment system of the national economic system.

3. The obtained three effects are summed up (GVA increase due to changes in $\mathrm{V}$ (financial rez.), V_trades, V_(transactions)) and the final potential value of the GVA increase of the type of economic activity under study is determined within the framework of the generated effects. 
4. The resulting increase is correlated with the actual level of gross value added for the reporting, analyzed period and the growth rate of the economic sector is calculated as a result of the penetration of blockchain technologies into the economic environment.

Based on the presented algorithmic actions in Table 3, Figure 2 shows similar estimates of the expected increase in gross value added due to the "blockchainization" of the economic environment in the context of the studied set of sectors of the Russian economy.

Table 3. Assessment of the influence of blockchain technologies on the parameters of gross value added (GVA) increase in the context of the studied set of sectors of the Russian economy, in \%

\begin{tabular}{|c|c|}
\hline Economic activity & GVA growth per year, $\%$ \\
\hline agriculture & 0.24 \\
\hline mining & 2.16 \\
\hline manufacturing industries & 0.87 \\
\hline trade & 0.0023 \\
\hline financial and insurance activities & 1.7 \\
\hline transportation and storage & 0.17 \\
\hline $\begin{array}{c}\text { public administration and military security; } \\
\text { social Security }\end{array}$ & 0.58 \\
\hline $\begin{array}{c}\text { activities in the field of health and social } \\
\text { services }\end{array}$ & 0.43 \\
\hline
\end{tabular}

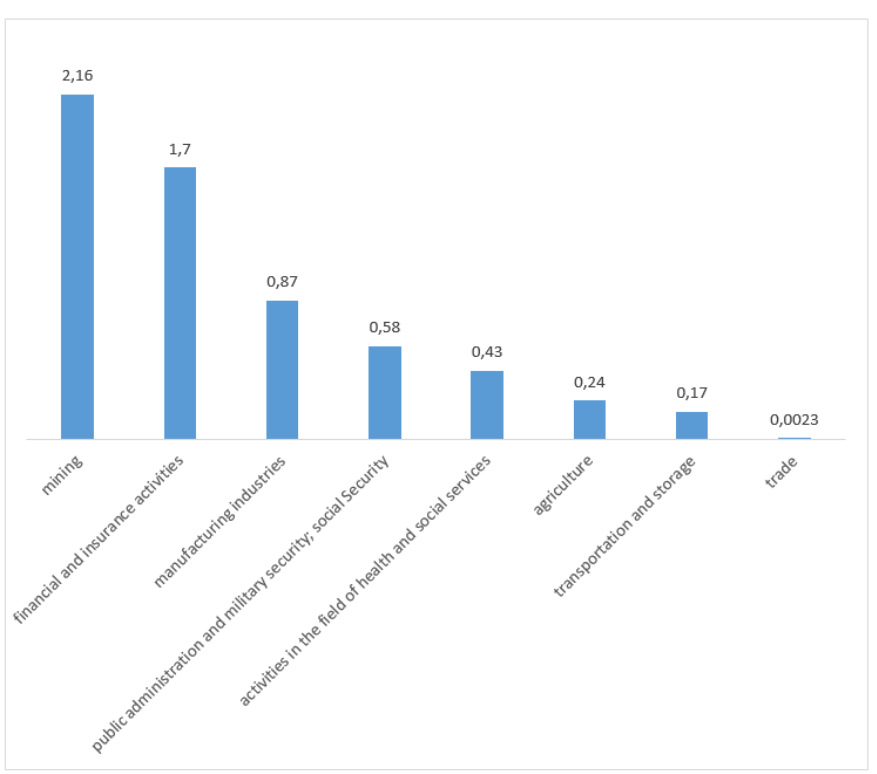

Fig. 2. Graphical illustration of the influence of blockchain technologies on the possible rate of increase of gross value added in the studied sectors of the economy in the framework of the analyzed baseline scenario, in $\%$ per year

\section{Summary}

The presented data show the presence of a differentiated response of the sectors of the economy to the changing institutional conditions of economic management, due to the diffusion of blockchain technologies. It is important to emphasize once again, that the estimates obtained are based on the basic scenario of the penetration of distributed data 
storage technologies into the socio-economic environment. This scenario provides for the minimum possible effects, that are formed with the penetration of blockchain technologies into the socio-economic environment, thereby practically ensuring possible results. Accordingly, a higher level of their integration into the economic environment will lead to more noticeable levels of dynamics of the development of the types of economic activity under study.

In general, it should be noted that, to the greatest extent, the integration of blockchain technologies into the economic environment affects such significant and structural sectors of the national economy as "Mining" and "Manufacturing industries". Together, they are amounted to about $25 \%$ of the GDP of the Russian Federation.

\section{Conclusions}

It is important to pay attention to the fact, that despite the identified differentiation, the sectors, included in the research sample, show a positive response to the "blockchainization" of the economy. This, in turn, confirms, based on the economic and mathematical apparatus, the previously put forward hypotheses and approaches of Russian and foreign researchers and experts about the presence of positive externalities from the integration of blockchain technologies into the economic environment. It is also important to note, that the results, obtained in the form of methodological approaches and empirical assessments of the sensitivity of industries to "blockchainization", were obtained on the basis of formalized research methods, which not only increases the level of their objectivity, but also forms the basis for predicting and forecasting the development of economic activity within the framework of the studied processes of integration of blockchain technologies into the national economic environment.

The research was supported by a grant from the Russian Science Foundation (project No. 19-1800202).

With the financial support of the Academy of Sciences of the Republic of Tatarstan (project No. 12-133-эГ).

\section{References}

1. The date of the launch of the national cryptocurrency of China has become known. $\mathrm{RBC}$, $04 / 16 / 2020$. https://www.rbc.ru/crypto/news/5e982b909a7947cba287a41b, free.

2. M.R. Safiullin, A.A. Abdukaeva, L.A. Elshin, Innovation 7(249), 41 (2019).

3. M.R. Safiullin, A.A. Abdukaeva, L.A. Elshin, Creative Economy 13(7), 1343 (2019)

4. E.A. Pekhtereva, Economic and social problems of Russia, 1(37), 71 (2018)

5. R.K. Nurmukhametov, P.D. Stepanov, T.R. Novikova, Financial Analytics: Science and Experience 11(2(344)), 179 (2018)

6. Yu.A. Konopleva, B.N. Kiseleva, S.E. Cheremnykh, Economics and management: problems, solutions 5 (4), 136 (2018)

7. H. Vranken, Current Opinion in Environmental Sustainability 28, 1 (2017)

8. K. J. Kim, S. P. Hong, Int. J. of Security and its Application 10(11), 201 (2016)

9. A.F. Bariviera, M.J. Basgall, W. Hasperué, M. Naiouf, Physica A 484, 82 (2017). https://doi-org.lcproxy.shu.ac.uk/10. 1016 / j.physa.2017.04.159 
10. L. Cocco, G. Concas, M. Marchesi, J. of Economic Interaction and Coordination 12(2), 345 (2017)

11. G. Pieters, S. Vivanco, Information Economics and Policy 39, 1 (2017)

12. G.O. Krylov, V.M. Seleznev, Problems of the security of the turnover of digital financial assets in cryptoeconomics: Monograph, 348 p. (M .: Prometheus, 2020)

13. G.O. Krylov, V.M. Seleznev, Finance: Theory and Practice 23(6), 26 (2019) https://doi.org/10.26794/2587-5671-2019-23-6-26-35

14. M.R. Safiullin, A.A. Abdukaeva, L.A. Elshin, M.V. Savushkin, Vestnik Universiteta 7, 154 (2020) 